\title{
PENGARUH INFRASTRUKTUR PEMBANGUNAN TERHADAP PERTUMBUHAN EKONOMI JAWA TIMUR
}

\section{Herlina Yakha Panama, Idah Zuhroh, Ida Nuraini}

Program Studi Ekonomi Pembangunan, Fakultas Ekonomi dan Bisnis, Universitas Muhammadiyah Malang, J1.Raya Tlogomas No.246 Malang, Indonesia

* Corresponding author: herlinapanama55@gmail.com

\begin{tabular}{l}
\hline Artikel Info \\
\hline Article history: \\
Received 08 June 2019 \\
Revised 20 June 2019 \\
Accepted 14 July 2019 \\
Available online 20 July \\
2019
\end{tabular}

Keyword: Infrastructur;
economic growth

JEL Classification

\begin{abstract}
This study aims to determine the effect of Infrastructure for Road, Electricity, Water, Education, and Health Development on the economic growth of the study of the NorthSouth Corridor of East Java Province in 2010-2017. The data used in this study is to use secondary data taken from 20102017. This study uses a multiple linear regression tool using panel data method by testing hypotheses such as F test, $t$ test, and Determination Coefficient R2. Based on the results of the study, it shows that Water, Electricity and Education Development Infrastructure has an effect on economic growth in the North-South Corridor Area of East Java while Road and Health Infrastructure does not affect Economic Growth in the North Corridor- South East Java Province. Water infrastructure has a positive and significant effect on economic growth. Electricity infrastructure has a positive and significant effect on economic growth. Educational infrastructure has a positive and significant effect on economic growth. Health Infrastructure has a negative and significant effect on economic growth. Based on the results of this study, it is necessary to have policies that can encourage infrastructure to help increase economic growth.
\end{abstract}

\section{PENDAHULUAN}

Jawa Timur sebagai salah satu indikator pembangunan yang diukur dengan produk domestik regional bruto (PDRB). Provinsi Jawa Timur sendiri terbagi menjadi 38 Kabupaten/Kota, yang terdiri dari 29 Kabupaten dan 9 kota. Infrastruktur berperan penting dalam mencapai pertumbuhan dan pembangunan ekonomi terutama di Koridor Ekonomi Jawa yang menjadi pusat kegiatan nasional dan berkontribusi besar terhadap pendapatan nasional. Pada tahun 2011 Koridor Ekonomi Jawa memiliki kontribusi sebesar 58\% terhadap Produk Domestik Bruto (PDB) Indonesia. Infrastruktur digolongkan menjadi tipe hard infrastructure dan soft infrastructure. Tipe hard infrastructure diantaranya meliputi jalan raya, jalan kereta api, pelabuhan, dan bandar udara. Tipe soft infrastructure meliputi saluran telepon, internet serta infrastruktur komunikasi dan infrastruktur institusi lainnya yang menjadi pelengkap tipe hard infrastructure (Beyzatlar dan Kustepeli, 2004).

Indonesia merupakan suatu negara berkembang dimana kondisi ekonomi sedang dalam tahap membangun serta dihadapkan beberapa permasalahan seperti permasalahan pengangguran, kependudukan dan ketenagakerjaan. Salah satu hal yang mempengaruhi dinamika pembangunan yang dilakukan oleh pemerintah yang terjadi di Indonesia yaitu kondisi kependudukan yang setiap tahunnya mengalami kenaikan penduduk serta tidak di imbangi oleh pemerataan penduduk. Apabila jumlah penduduk yang besar serta di ikuti 
dengan kualitas penduduk yang memadai maka hal itu akan bisa terjadi pendorong dalam hal pembangunan ekonomi. Semua sektor masih belum berfungsi dengan baik serta belum meratanya pembangunan di semua bidang maka akan berakibat kepada ketersediaan terhadap lapangan pekerjaan yang dikatakan belum mencukupi kebutuhan (Abdullah, 2018). Upah yang rendah dan tingkat pengangguran yang sangat tinggi serta ditambahnya penduduk yang terus meningkat merupakan masalah dasar tentang ketenagakerjaan yang terjadi di Indonesia (Arifin 2010).

Provinsi Jawa Timur perekonomian dapat dikatakan memuaskan yaitu terjadi pada tahun 2011. Kemudian pada tahun 2012 pertumbuhan ekonomi di Provinsi Jawa Timur mencapai 7,5 persen, dengan hasil tersebut di lihat dari beberapa pengamat bahwa akan terjadi realisasi pengembangan wilayah dan pembangunan dikarenakan di provinsi ini mempunyai suatu karakter yang kuat dibandingkan dengan wilayah lain. Hal ini dapat menunjukkan potensi yang dimiliki Provinsi Jawa Timur yang di tunjukkan dari nilai PDRB nya memiliki peran yang cukup strategis di tataran nasional. Pertumbuhan ekonomi yang tinggi tersebut dapat tumbuh lebih besar lagi jika di topang oleh keterkaitan antar sektor perekonomian yang baik. Sebaliknya jika terjadi kesenjangan maka hal ini pada akhirnya akan dapat menimbulkan beberapa permasalahan yang dalam konteks makro sangat merugikan dalam proses pembangunan suatu wilayah yang ingin dicapai.

Pertumbuhan ekonomi adalah suatu ukuran kuantitatif yang menggambarkan perkembangan suatu perekonomian dalam suatu tahun tertentu apabila dibandingkan dengan tahun sebelumnya (Sukirno, 2011). Produk Domestik Bruto (PDB) adalah pendapatan total dan pengeluaran total nasional atas output barang dan jasa pada periode tertentu (Mankiw, 2003). Suatu perekonomian dikatakan mengalami pertumbuhan ekonomi jika jumlah produksi barang dan jasanya meningkat. Namun, sangat sulit mencatat jumlah unit barang dan jasa yang dihasilkan selama periode tertentu sehingga angka yang digunakan untuk menaksir output adalah nilai moneternya (uang) yang tercermin dalam nilai Produk Domestik Bruto (PDB) (Sukirno, 2013).

Infrastruktur jalan sangat penting untuk menunjang kegiatan ekonomi di Koridor Ekonomi Jawa. Banyak manfaat ekonomi diperoleh dari infrastruktur antara lain pendapatan, aksesibilitas, lapangan kerja saat konstruksi jalan, reduksi biaya transportasi, penghematan biaya dan waktu, dan meningkatkan produktivitas industri (Kim, 2006). Bidang ekonomi adalah hal penting yang terus menerus diperhatikan oleh pemerintah. Tujuan negara dalam ekonomi makro adalah untuk mencapai stabilitas ekonomi, pertumbuhan, dan pembangunan ekonomi yang tinggi. Pada hakekatnya pembangunan harus mencerminkan perubahan total suatu masyarakat menuju suatu kondisi kehidupan yang lebih baik (Todaro dan Smith 2006)

Indonesia merupakan salah satu negara sedang berkembang yang ditandai dengan sebagian besar masyarakatnya miskin, terjerat dalam lingkaran utang luar negeri dan tingkat pengangguran yang tinggi. Permasalahan tersebut tidak cukup diatasi dengan laju pertumbuhan ekonomi yang tinggi. Oleh karena itu laju pertumbuhan ekonomi yang tinggi bukan jaminan yang dapat menyejahterakan masyarakatnya (Suliswanto, 2015). 
Peningkatan pertumbuhan penduduk yang tinggi menyebabkan naiknya jumlah penduduk yang besar hal ini dapat mengakibatkan tingginya intensitas dari tenaga kerja. Tenaga kerja merupakan input dimana tidak hanya memiliki dalam segi fisik saja akan tetap juga mempunyai daya pikir serta perasaan, faktor produksi tenaga tenaga kerja dinilai sangat amat penting dimana proses produksi tidak dapat bekerja tanpa adanya unsur manusia (Sudarti, 2018). Apabila tingginya intensitas tenaga kerja yang semakin besar serta tidak dibarengi dengan adanya kesempatan kerja yang terbatas maka dapat menyebabkan naiknya tingkat pengangguran yang tersedia. Tersedianya lapangan pekerjaan dapat dilakukan dengan penambahan modal sehingga berdamak positif terhadap perkembangan untuk penyediaan lapangan pekerjaan ( Kusuma, 2017).

Investasi merupakan salah satu yang dibutuhkan dalam pertumbuhan ekonomi. Investasi bisa diartikan sebagai pengeluaran perusahaan atau pengeluaran penanaman modal perusahaan yang digunakan untuk membeli suatu barang atau perlengkapan produksi untuk meningkatkan kemampuan dalam memproduksi suatu barang atau jasa yang tersedia di dalam perekonomian (Sukirno, 2013). Dengan adanya investasi dapat mendorong terciptanya barang modal baru sehingga bisa menyerap faktor produksi, yang pada intinya dapat memperluas lapangan pekerjaan yang dapat menyerap faktor tenaga kerja atau kesempatan kerja sehingga dapat mengurangi pengangguran yang tersedia

Pertumbuhan ekonomi suatu wilayah juga tidak terlepas dari pertumbuhan masing-masing sektor dalam menyerap tenaga kerja. Indikator perekonomian suatu wilayah dapat dilihat dari Produk Domestik Regional Bruto (PDRB) baik secara atas dasar harga berlaku ataupun atas dasar harga konstan. PDRB merupakan jumlah unit suatu barang yang dihasilkan dalam suatu daerah atau jumlah barang dan jasa yang dihasilkan dari seluruh kegiatan perkonomian (BPS, 2017). PDRB atas dasar harga berlaku merupakan gambaran jumlah nilai suatu barang dan jasa yang dihitung berdasarkan harga berlaku setiap tahun serta digunakan untuk melihat struktur ataupun pergeseran ekonomi sedangkan untuk PDRB atas dasar harga konstan merupakan jumlah nilai suatu barang ataupun jasa yang dihitung berdasarkan harga berlaku pada satu tahun sebagai dasar serta digunakan untuk mengetahui pertumbuhan ekonomi setiap tahunnya.

Kinerja perekonomian suatu negara umumnya diukur oleh beberapa indikator ekonomi yang bisa mencerminkan tingkat kegiatan ekonomi di masyarakat. Perkembangan indikatorindikator ini tidak saja dapat berpengaruh pada tingkat stabilitas ekonomi, tetapi juga pada tingkat kesejahteraan masyarakat secara keseluruhan. Salah satu indikator ekonomi terpenting adalah pertumbuhan ekonomi, yang untuk pencapaiannya dapat dipengaruhi oleh tersedianya pembiayaan yang memadai (Arifin, 2012). Pertumbuhan ekonomi telah lama dijadikan sebagai indikator keberhasilan pembangunan ekonomi. Namun demikian, yang sering terjadi adalah tingginya pertumbuhan ekonomi yang tidak diikuti dengan pemerataan pendapatan. Oleh sebab itu perlu adanya pengembangan konsep pembangunan ekonomi yang tidak hanya 
memakai indikator pertumbuhan ekonomi tetapi pertumbuhan ekonomi yang berkualitas yang memasukkan dimensi pemerataan pendapatan (Arfrida, 2010)

Infrastruktur dibagi menjadi 3 yaitu pertama, infrastruktur ekonomi, merupakan aset fisik yang menyediakan jasa dan digunakan dalam produksi dan konsumsi final meliputi public utilities (telekomunikasi, air minum, sanitasi, dan gas), public works (bendungan, saluran irigasi dan drainase) serta sektor transportasi (jalan, kereta api, angkutan pelabuhan dan lapangan terbang). Kedua, infrastruktur sosial, merupakan aset yang mendukung kesehatan dan keahlian masyarakat meliputi pendidikan (sekolah, dan perpustakaan), kesehatan (rumah sakit, pusat kesehatan) serta untuk rekreasi (tanah, museum, dan lain-lain). Ketiga, infrastruktur administrasi/instansi, meliputi penegak hukum, kontrol administrasi dan koordinasi serta kebudayaan.

Menurut APWA (American Public Works Association) komponen komponen di dalam infrastruktur yaitu :

a. Sistem penyediaan air : waduk, penampungan air, transmisi dan distribusi, fasilitas pengolahan air (water treatment).

b. Sistem pengelolaan air limbah : pengumpul, pengolahan, pembuangan, daur ulang

c. Fasilitas pengelolaan limbah padat,

d. Fasilitas pengendalian banjir, drainase dan irigasi,

e. Fasilitas lintas air dan navigasi,

f. Fasilitas transportasi: jalan, rel, bandara udara (termasuk tanda-tanda lalu lintas dan fasilitas pengontrol),

g. Sistem kelistrikan: produksi dan distribusi,

h. Gedung publik: sekolah, rumah sakit

i. Fasilitas perumahan publik,

\section{Perumusan Hipotesis}

Hipotesis merupakan jawaban yang bersifat sementara terhadap penelitian hingga bukti dimana melalui data yang sudah terkumpul. Menurut kerangka pemikiran diatas, penelitian merumuskan bahwa hipotesis pada penelitian sebagai berikut :

H1 : Di duga bahwa pengaruh Infarstruktur jalan berpengaruh signifikan terhadap pertumbuhan ekonomi di Kawasan Koridor Utara-Selatan.

H2 : Di duga bahwa pengaruh Infrastruktur Air berpengaruh signifikan terhadap pertumbuhan ekonomi di Kawasan Koridor Utara-Selatan.

H3 : Di duga bahwa pengaruh Infrastruktur Listrik berpengaruh signifikan terhadap pertumbuhan ekonomi di Kawasan Koridor Utara-Selatan.

H4 : Di duga bahwa pengaruh Infrastruktur Pendidikan berpengaruh signifikan terhadap pertumbuhan ekonomi di Kawasan Koridor Utara-Selatan.

H5 : Di duga bahwa pengaruh Infrastruktur Kesehatan berpengaruh signifikan terhadap pertumbuhan ekonomi di Kawasan Koridor Utara-Selatan.

\section{METODE PENELITIAN}

Pada penelitian ini data yang dipakai adalah data panel, data panel merupakan gabungan dari data time series dengan data cross section. Penelitian ini memilih lokasi yang berada di 8 kabupaten atau kota di Kawasan Utara- 
Selatan Provinsi Jawa Timur. Jenis penelitian ini bersifat deskriptif kuantitatif yakni menggunakan angka serta memberikan hasil secara akurat serta faktual terhadap data yang sudah ada. Penelitian ini juga tidak hanya menggunakan data akan tetapi juga menginterpetasi serta menganalisa terhadap data tersebut. Penelitian ini menggunakan data sekunder.

Rumus regeresi data panel :

Dimana :

$$
\log Y_{1 i t}=\propto+\beta_{1} X_{1 i t}+\beta_{2} X_{2 i t}+\beta_{3} X_{3 i t}+\beta_{4} X_{4 i t}+\beta_{5} X_{5 i t}
$$

$$
\begin{array}{ll}
\log Y_{1} & =\text { Pertumbuhan Ekonomi } \\
\propto & =\text { Konstanta } \\
\beta_{1} \beta_{2} \beta_{3} & =\text { Koefisien Garis Regresi } \\
X_{1} & =\text { Infrastruktur Jalan } \\
X_{2} & =\text { Infrastruktur listrik } \\
X_{3} & =\text { Infrastruktur Air } \\
X_{4} & =\text { Infrastruktur Pendidikan } \\
X_{5} & =\text { Infrastruktur Kesehatan } \\
\mathrm{i} & =\text { Data Cross-Section " Koridor Utara-Selatan" } \\
\mathrm{t} & =\text { Data Time Series tahun 2010-2017 }
\end{array}
$$

Terdapat 3 (tiga) pendekatan dalam melakukan metode estimasi regresi data panel, diantaranya :

a. Common Effect Model atau Pooled Least Square (PLS) :

Model data ini merupakan model data panel yang sangat sederhana dikarenakan hanya menggabungkan dari dua data yakni data time series serta data cross section. Dalam metode model ini juga bisa menggunakan pendekatan OLS (Ordinary Least Square) sebagai estimasi dalam model data panel.

b. Fixed Effect Model (FE) :

Model data ini dapat diasumsikan bahwa terdapat perbedaan antar individu memfasilitasi terhadap perbedaan intersepnya, namun slopnya tidak berubah atau masih sama antar variabel. Dalam model estimasi ini menggunakan LSDV (Least Square Dummy Variabel).

c. Random Effect Model (RE) :

Untuk model ini akan mengestimasi dari data panel dimana terjadi gangguan variabel atau bisa saling berhubungan antar waktu serta antar individu. Dalam model ini perbandingan intersep diakomodasi oleh error term terhadap masing-masing individu. Estimasi model atau perhitungan dalam model ini yaitu menggunakan GLS (Generalized Least Square).

\section{A. Penentuan Model Estimasi :}

Dalam pemilihan model yang tepat serta akurat. Maka ada beberapa pengujian yang dapat dilakukan, yaitu : 

a.) Uji Chow
b.) Uji Hausman
c.) Uji Lagrange Multiplier

\section{B. Pengujian hipotesis}
a.) Uji t
b.) $\mathrm{Uji} F$
c.) Koefisien Determinasi / R-Squared $\mathrm{R}^{2}$

\section{HASIL DAN PEMBAHASAN}

Koridor Utara-Selatan merupakan daerah yang menjadi pusat perekonomian yang berada di Provinsi Jawa Timur. Dalam rencana wilayah terbagi menjadi beberapa tata ruang berdasarkan satuan wilayah pembangunan atau SWP yang terbagi menjadi 8 Kabupaten atau kota di Kawasan Koridor Utara-Selatan. Kelompok wilayah tersebut diantaranya, Gresik, Surabaya, Sidoarjo, Mojokerto, Pasuruan, Malang, Blitar dan Batu.

Berdasarkan dari hasil analisis pemilihan regresi data panel yang sudah dilakukan dengan menggunakan Uji Chow, Uji Hausman serta Uji LM atau Langrange Multiplier. Di peroleh hasil bahwa pada penelitian ini menggunakan metode Common Effect Model (CE). Berikut ini adalah hasil analisis regresi data panel $\mathrm{FE}$ dengan diolah menggunakan Eviews 9 yang dapat dijelaskan sebagai berikut.

\section{Tabel 1. Pemilihan Model Terbaik Common Effect (FE)}

\begin{tabular}{|c|c|c|}
\hline \multicolumn{3}{|c|}{ Hasil Model Fixed Effect } \\
\hline Jalan & -0.130736 & 0.4216 \\
\hline Listrik & 0.135520 & 0.0454 \\
\hline Air & 0.838911 & 0.0000 \\
\hline Pendidikan & 0.107798 & 0.0324 \\
\hline Kesehatan & -0.100171 & 0.7273 \\
\cline { 1 - 2 } R-Squared & 0.993950 & \\
\cline { 1 - 2 } F-statistic & 0.992527 & \\
\cline { 1 - 2 } Prob(F-statistic) & 0.000000 \\
\cline { 1 - 2 }
\end{tabular}

Sumber: Data diolah menggunakan Eviews 9, 2019

Berdasarkan dari hasil uji regresi data panel dengan menggunakan Common Effect Model diatas sebagai pemilihan model yang tepat, maka pengujian model dan hipotesis yang dilakukan dapat dijelaskan sebagai berikut.

Maka didapatkan hasil analisis regresi sebagai berikut :

$L Y=-3.4354586-0.130736 \mathrm{X} 1+0.135520 \mathrm{X} 2+0.838911 \mathrm{X} 3+0.107798 \mathrm{X} 4-$ $0.100171 X 5$.

\section{Pembahasan Estimasi}

1. Konstanta $(\alpha)$ sebesar -3.435458 menjelaskan bahwa ketika Infrastruktur Jalan, Air, Listrik, Pendidikan dan Kesehatan sama dengan nol atau konstan maka Pertumbuhan ekonomi akan mengalami kenaikan sebesar 3.435458 Juta rupiah. 
2. $\beta_{1}$ (Infrastruktur Jalan) sebesar -0.130736 , berarti koefisien regresi variabel Jalan (X1) sebesar-0.130736 . Jadi ada ada Hubungan yang negative dan tidak signifikan antara Jalan terhadap Pertumbuhan ekonomi (Y) sebesar -0.130736. Jika Infrastruktur Jalan (X1) naik sebesar 1\% maka Pembiayaan akan turun sebesar 0.130736 Juta Rupiah sedangkan jika Infrastruktur Jalan (X1) turun sebesar 1\% maka Pertumbuhan ekonomi akan naik sebesar 0.130736Juta rupiah dengan asumsi variabel lainnya konstan (ceteris paribus).

3. $\beta_{2}$ (Infrastruktur Air) sebesar 0.135520 , koefisien regresi variabel Infrastruktur Air sebesar 0.135520. Hal ini menunjukkan adanya pengaruh yang positif antara Infrastruktur Air terhadap Pertumbuhan ekonomi (Y) sebesar 0.135520. Jika Infrastruktur Air (X2) naik sebesar 1 Juta Rupiah maka Pertumbuhan ekonomi akan naik sebesar 0.135520 Juta Rupiah sedangkan jika Infrastruktur Air (X2) turun sebesar 1 Juta rupiah maka Pertumbuhan ekonomi akan turun sebesar 0.135520 Juta rupiah dengan asumsi variabel lainnya konstan (ceteris paribus).

4. $\beta_{3}$ (Infrastruktur listrik) sebesar, 0.838911 koefisien regresi variabel Infrastruktur listrik sebesar 0.838911. Hal ini menunjukkan adanya pengaruh yang positif antara Infrastruktur listrik terhadap Pertumbuhan ekonomi (Y) sebesar 0.838911. Jika Infrastruktur Listrik (X3) naik sebesar 1\% maka Pertumbuhan ekonomi akan turun sebesar 0.838911 Juta rupiah sedangkan jika Infrastruktur Listrik(X3) turun sebesar $1 \%$ maka Pembiayaan akan naik sebesar 0.838911 Juta rupiah dengan asumsi variabel lainnya konstan (ceteris paribus).

5. $\quad \beta_{4}$ (Infrastruktur Pendidikan) sebesar 0.107798 , koefisien regresi variabel Infrastruktur Pendidikan sebesar 0.107798 . Hal ini menunjukkan adanya pengaruh yang Positif antara Infrastruktur Pendidikan terhadap Pertumbuhan ekonomi (Y) sebesar 0.107798. Jika Infrastruktur Pendidikan (X4) naik sebesar 1\% maka Pembiayaan akan turun sebesar 0.107798 Juta rupiah sedangkan jika Infrastruktur Pendidikan (X4) turun sebesar 1\% maka Pertumbuhan ekonomi akan naik sebesar 0.107798 Juta rupiah dengan asumsi variabel lainnya konstan (ceteris paribus).

6. $\beta_{5}$ (Infrastruktur Kesehatan) sebesar -0.100171 , berarti koefisien regresi variabel Infrastruktur Kesehatan (X5) sebesar-0.100171. Jadi ada ada Hubungan yang negative tidak signifikan antara Infrastruktur Kesehatan terhadap Pertumbuhan ekonomi (Y) sebesar -0.100171. Jika Infrastruktur kesehatan (X5) naik sebesar 1\% maka Pertumbuhan ekonomi akan turun sebesar 0.100171Juta Rupiah sedangkan jika Infrastruktur Kesehatan (X5) turun sebesar 1\% maka Pertumbuhan ekonomi akan naik sebesar 0.100171 Juta rupiah dengan asumsi variabel lainnya konstan (ceteris paribus).

Berikut ini adalah penjelasan pengaruh dari masing-masing variabel independent (bebas) seperti Infrastruktur Jalan (X1), Infrastruktur Air (X2), Infrastruktur Listrik (X3), Infrastruktur Pendidikan (X4) dan Infrastruktur Kesehatan (X5) terhadap variabel dependent (terkait) yaitu pertumbuhan ekonomi (Y).

\section{Pengaruh infrastruktur Jalan Terhadap Pertumbuhan ekonomi}


Pengaruh Infrastruktur Jalan terhadap Pertumbuhan ekonomi adalah negatif signifikan, dari hasil pengujian yang sudah dilakukan dengan hasil (uji t) -0.810228 sedangkan nilai coefficient -0.130736 dan nilai profitabilitas sebesar 0.4216 , hal ini sesuai hal ini sesuai dengan Permasalahn yang dihadapi dalam pengembangan jalan antara lain belum optimalnya pengendara jalan dalam mempergunakan jalan dengan sebaik-baiknya. Jalan dalam kondisi rusak diakibatkan banyaknya mobil-mobil besar yang lalu lalang melewati jalan tanpa aturan. Dan perbaikan jalan setiaptahunnya, pemerintah mengeluarkan biaya yang tidak sedikit agar kondisi jalan selalu dalam keadaan baik.

Penelitian ini sama dengan teori Dollow yang menyatakan bahwa jalan memiliki pengaruh yang tidak signifikan terhadap pertumbuhan ekonomi, karena teori solow menyatakan bahwa hanya terdapat berbagai jenis capital. Perusahaan privat melakukan investasi pada berbagai bentuk capital public yaitu infrastruktur seperti jalan, jembatan, dan saluran pembuangan. Selain itu penelitian ini sama juga dengan penelitian sebelumnya yaitu: wylie (1996), Agenor (2009) dimana semua penelitian tersebut menjelaskan bahwa jalan memiliki pengaruh yang positif akan tetapi tidak signifikan terhadap pertumbuhan ekonomi di suatu daerah.

\section{Pengaruh Infrastruktur Air Terhadap Pertumbuhan ekonomi}

Pengaruh Infrastruktur Air Terhadap Pertumbuhan ekonomi adalah positif signifikan dari hasil pengujian yang sudah dilakukan dengan hasil (uji t) 2.051133 sedangkan nilai coefficient 0.135520 dan nilai profitabilitas sebesar 0.0454. hal ini Air juga mempunyai pengaruh yang besar positif dan signifikan terhadap pertumbuhan ekonomi karena dengan terpenuhinya kebutuhan akan air akan memberikan fasilitas dalam menstransformasi nontradable goods menjadi tradable goods dan atau dari sector pertanian menjadi jasa dan manufaktur

\section{Pengaruh Infrastruktur Listrik Terhadap Pertumbuhan ekonomi}

Pengaruh Infrastruktur Listrik Terhadap Pertumbuhan ekonomi adalah positif signifikan dari hasil pengujian yang sudah dilakukan dengan hasil (uji t) 7.805983 sedangkan nilai coefficient 0.838911 dan nilai profitabilitas sebesar 0.0000. Listrik mempunyai pengaruh yang besar, positif dan signifikan terhadap pertumbuhan ekonomi karena dengan adanya listrik maka investor akan berinvestasi, karena listrik merupakan salah satu fasilitas yang mengefisienkan proses produksi.

\section{Pengaruh Infrastruktur Pendidikan Terhadap Pertumbuhan ekonomi}

Pengaruh infrastruktur pendidikan terhadap pertumbuhan ekonomi adalah positif signifikan dari hasil pengujian yang sudah dilakukan dengan hasil (uji t) 2.200080 sedangkan nilai coefficient 0.107798 dan nilai profitabilitas sebesar 0.0324. Akhirnya dapat disimpulkan bahwa pendidikan mempunyai pengaruh terhadap pertumbuhan ekonomi suatu bangsa. Implikasinya, semakin tinggi pendidikan, hidup manusia akan semakin berkualitas. Dalam kaitannya dengan perekonomian secara umum (nasional), semakin tinggi kualitas hidup suatu bangsa, semakin tinggi tingkat pertumbuhan dan kesejahteraan bangsa tersebut.

\section{Pengaruh Infrastruktur Kesehatan Terhadap Pertumbuhan ekonomi}


Pengaruh Infrastruktur Kesehatan terhadap Pertumbuhan ekonomi adalah negatif signifikan, dari hasil pengujian yang sudah dilakukan dengan hasil (uji t) -0.350650 sedangkan nilai coefficient -0.100171 dan nilai profitabilitas sebesar0.7273, hal ini sesuai Berdasarkan pengalaman di beberapa negara, Todaro (2000) membuktikan bahwa Kesehatan memang memiliki pengaruh yang positif akan tetapi tidak signifikan terhadap promosi pertumbuhan ekonomi.

\section{KESIMPULAN}

Pada penelitian yang sudah dilakukan di atas, penelitian ini bertujuan untuk mengetahui pengaruh antara variabel Infrastruktur jalan, Listrik, Air, Pendidikan dan Kesehatan terhadap pertumbuhan ekonomi berdasarkan Kabupaten atau Kota di Kawasan Koridor Utara-Selatan Jawa Timur tahun 2010-2017. Maka penelitian ini mengambil kesimpulan diantaranya sebagai berikut.

1. Infrastuktur Jalan menunjukkan tidak berpengaruh signifikan terhadap perumbuhan ekonomi di koridor Utara-Selatan Jawa Timur dengan nilai koefisien regresi sebesar -0.130736 dan nilai probabilitas $0.4216>0,05$. Dengan dilaksanakannnya desentralisasi jalan maka pemerintah daerah memiliki kewenangan yang lebih luas untuk membangun jalan dan memperbaiki jalan yang rusak di suatu daerah. Sehingga jalan memiliki konstribusi yang positif terhadap prosespembentukan kualitas dan kuantitas yang berdampak pada peningkatan pertumbuhan ekonomi di daerah tersebut

2. Infrastruktur Air dari pengujian hipotesis dapat dilihat bahwa dapat berpengaruh signifikan terhadap pertumbuhan ekonomi dengan nilai koefisien regresi sebesar 0.135520 dan nilai probabilitas $0.0454<0.05$. Sebagai salah satu wujud pelaksanaan penyediaan air bersih di daerahdaerah pedaleman adalah suatu salah satu sumber utama bagi daerahdaerah pedaleman untuk melakukan aktivitasnya. Hal ini membuat pemerintah daerah semakin meningkatkan penyediaan air bersih guna meningkatkan pertumbuhan ekonomi didaerah tersebut.

3. Infrastruktur Listrik dari pengujian hipotesis dapat dilihat bahwa dapat berpengaruh signifikan terhadap pertumbuhan ekonomi dengan nilai koefisien regresi sebesar 0.838911 dan nilai probabilitas $0.0000<0.05$. hal salah satu wujud pelaksanaan penyediaan listrik di daerah-daerah pedaleman adalah suatu salah satu sumber utama bagi daerah-daerah pedaleman untuk melakukan aktivitasnya. Hal ini membuat pemerintah daerah semakin meningkatkan penyediaan Listrik guna meningkatkan pertumbuhan ekonomi didaerah tersebut.

4. Infrastruktur Pendidikan berpengaruh signifikan dan positif terhadap pertumbuhan ekonomi dengan nilai koefisien regresi sebesar 0.107798 dan nilai probabilitas $0.0324<0.05$. karena dapat disimpulkan bahwa pendidikan mempunyai pengaruh terhadap pertumbuhan ekonomi suatu bangsa. Implikasinya, semakin tinggi pendidikan, hidup manusia akan semakin berkualitas. Dalam kaitannya dengan perekonomian secara umum (nasional), semakin tinggi kualitas hidup suatu bangsa, semakin 
tinggi tingkat pertumbuhan dan kesejahteraan bangsa tersebut.

5. Infrastruktur Kesehatan berpengaruh signifikan dan positif terhadap pertumbuhan ekonomi dengan nilai koefisien sebesar -0.10017 dan nilai probabilitas $0.7273<0.05$. karena Disamping itu perbaikan di bidang kesehatan akan berdampak pada capaian pembangunan manusia. $\mathrm{Hal}$ ini mengingat indikator dalam indeks pembangunan manusia (IPM) oleh UNDP menempatkan kesehatan sebagai indikator utama disamping indikator ekonomi. Pendek kata pembangunan manusia telah memberikan sumbangan terbesar bagi pencapaian keberlangsungan pembangunan

\section{SARAN}

Dalam penelitian ini sebagai penutup untuk penulisan skripsi ada beberapa saran yang diberikan, diantaranya.

1. Infrastruktur Jalan, Air, Listrik, Pendidikan Dan Kesehatan sebagai bagian penting dalam mendorong kinerja pertumbuhan ekonomi suatu wilayah atau daerah, maka pemerintah sebaiknyass memberikan perhatian khusus terhadap perkembangan infrastruktur jalan, air, listrik, pendidikan dan kesehatan agar kualitas dan kuantitasnya dapat memberikan manfaat terhadap masyarakat di koridor utara-selatan JawaTimur sehingga nantinya akan memberikan kesejahteraan bagi masyarakat dan dapat meningkatkan pertumbuhan ekonomi.

2. Untuk mencapai pertumbuhan ekonomi yang berkualitas dan berkelanjutan, maka diperlukan kebijakan-kebijakan yang dapat mendorong agar infrastruktur dapat membantu peningkatan pertumbuhan ekonomi dan pemerintah Jawa Timur harus mampu membuat infrastruktur yang nantinya dapat meningkatkan pertumbuhan ekonomi, serta manfaat dari peningkatan infrastruktur tersebut dapat juga dirasakan oleh masyarakat, karena pertumbuhan ekonomi yang tinggi harus diimbangi dengan kesejahteraan masyarakat yang merata.

\section{DAFTAR PUSTAKA}

Di, T., \& Dan, P. (2018). Muhammad Ardiansyah 1 ), Idah Zuhroh 2 ), M. Faisal Abdullah 3 ). 2, 294-308.

Gresik, K. (2018). Analisis Tingkat Penyerapan Tenaga Kerja Sektor Industri Di Kabupaten Gresik. 2, 74-82.

Indradewa, I. G. A., \& Natha, K. S. (2013). " Pengaruh Inflasi , PDRB Dan Upah Minimum Terhadap Penyerapan Tenaga Kerja Di Provinsi Bali " PENDAHULUAN Pembangunan nasional di Indonesia tidak dapat dilepaskan dari pembangunan daerah, karena wilayah Indonesia terdiri atas provinsi-provinsi , kabupat. Economics Development Analysis Journal, 923950.

Mankiw, Gregory N. 2007. Makro Ekonomi Edisi Keenam. Erlangga: Jakarta. 
Nurrohman, R., \& Arifin, Z. (2010). Analisis Pertumbuhan Ekonomi Dan Penyerapan Tenaga Kerja Di Provinsi Jawa Tengah. Jurnal Ekonomi Pembangunan, 8(1), 247. https://doi.org/10.22219/jep.v8i1.3600

Rusniati, R., Sudarti, S., \& Agustin, A. F. (2018). Analisis Pengaruh Pertumbuhan Ekonomi dan Upah Minimum terhadap Penyerapan Tenaga Kerja di Kabupaten Malang. FALAH: Jurnal Ekonomi Syariah, 3(2), 34. https://doi.org/10.22219/jes.v3i2.7232

Sanaubar, G. (2017). Pengaruh Potensi Pariwisata Terhadap Penyerapan Tenaga Kerja Sektor Perhotelan Di 9 Kabupaten/Kota Provinsi Jawa Timur Tahun 2012-2015. 1, 324-339.

Studenmund, A. H. 2014. Using Econometric A Practical Guide. Edinburgh: Pearson Education

Sukirno, Sadono. 2013. Makroekonomi Teori Pengantar. Yogyakarta: Rajagrafindo Persada.

Sulistiawati, R. (2012). Pengaruh Upah Minimum Terhadap Penyerapan Tenaga Kerja dan Kesejahteraan Masyarakat di Provinsi di Indonesia. Jurnal Eksos, 8, 195-211.

Wasilaputri, F. R. (2016). Pengaruh Upah Minimum Provinsi, PDRB Dan Investasi Terhadap Penyerapan Tenaga Kerja Di Pulau Jawa Tahun 20102014 | Wasilaputri | Jurnal Pendidikan dan Ekonomi. Jurnal Pendidikan Dan Ekonomi, 5(3), 243-250. Retrieved from http://journal.student.uny.ac.id/ojs/ojs/index.php/ekonomi/article/view/4 $\underline{086}$ 